\title{
Role of PITRM1 in Mitochondrial Dysfunction and Neurodegeneration
}

\author{
Dario Brunetti $^{1,2}$ (D), Alessia Catania ${ }^{2}$, Carlo Viscomi ${ }^{3}$, Michela Deleidi ${ }^{4}$, Laurence A. Bindoff ${ }^{5,6}$, \\ Daniele Ghezzi $2,7, *$ (D) and Massimo Zeviani $8,9, *$ (D)
}

1 Department of Medical Biotechnology and Translational Medicine, University of Milan, 20129 Milan, Italy; dario.brunetti@unimi.it

2 Unit of Medical Genetics and Neurogenetics, Fondazione IRCCS Istituto Neurologico Carlo Besta, 20126 Milan, Italy; alessia.catania@istituto-besta.it

3 Department of Biomedical Sciences, University of Padova, 35131 Padova, Italy; carlo.viscomi@unipd.it

4 German Center for Neurodegenerative Diseases (DZNE), 72076 Tübingen, Germany; michela.deleidi@dzne.de

5 Neuro-SysMed, Center of Excellence for Clinical Research in Neurological Diseases, Haukeland University Hospital, N-5021 Bergen, Norway; laurence.albert.bindoff@helse-bergen.no

6 Department of Clinical Medicine, University of Bergen, N-5021 Bergen, Norway

7 Department of Pathophysiology and Transplantation, University of Milan, 20122 Milan, Italy

8 Department of Neurosciences, University of Padova, 35128 Padova, Italy

9 Venetian Institute of Molecular Medicine, 35128 Padova, Italy

* Correspondence: daniele.ghezzi@unimi.it (D.G.); massimo.zeviani@unipd.it (M.Z.)

check for updates

Citation: Brunetti, D.; Catania, A.; Viscomi, C.; Deleidi, M.; Bindoff, L.A.; Ghezzi, D.; Zeviani, M. Role of PITRM1 in Mitochondrial Dysfunction and Neurodegeneration. Biomedicines 2021, 9, 833. https:// doi.org/10.3390/biomedicines9070833

Academic Editor: Susana Cardoso

Received: 7 June 2021

Accepted: 15 July 2021

Published: 17 July 2021

Publisher's Note: MDPI stays neutral with regard to jurisdictional claims in published maps and institutional affiliations.

Copyright: (c) 2021 by the authors. Licensee MDPI, Basel, Switzerland. This article is an open access article distributed under the terms and conditions of the Creative Commons Attribution (CC BY) license (https:// creativecommons.org/licenses/by/ $4.0 /)$.

\begin{abstract}
Mounting evidence shows a link between mitochondrial dysfunction and neurodegenerative disorders, including Alzheimer Disease. Increased oxidative stress, defective mitodynamics, and impaired oxidative phosphorylation leading to decreased ATP production, can determine synaptic dysfunction, apoptosis, and neurodegeneration. Furthermore, mitochondrial proteostasis and the protease-mediated quality control system, carrying out degradation of potentially toxic peptides and misfolded or damaged proteins inside mitochondria, are emerging as potential pathogenetic mechanisms. The enzyme pitrilysin metallopeptidase 1 (PITRM1) is a key player in these processes; it is responsible for degrading mitochondrial targeting sequences that are cleaved off from the imported precursor proteins and for digesting a mitochondrial fraction of amyloid beta (A $\beta)$. In this review, we present current evidence obtained from patients with PITRM1 mutations, as well as the different cellular and animal models of PITRM1 deficiency, which points toward PITRM1 as a possible driving factor of several neurodegenerative conditions. Finally, we point out the prospect of new diagnostic and therapeutic approaches.
\end{abstract}

Keywords: PITRM1; pitrilysin metallopeptidase 1; mitochondrial proteostasis; Alzheimer Disease; neurodegeneration; neurodegenerative diseases; neurodegenerative dementia; spinocerebellar ataxia; mitochondrial protein quality control; protein aggregation; mitochondrial dysfunction

\section{Introduction}

Mitochondrial dysfunction, whether primary or secondary, is increasingly recognized as a hallmark of neurodegeneration [1] and a wide body of literature provides evidence of impaired mitochondrial function as a cause rather than a consequence of neurodegeneration [2-4]. Mitochondrial demise can be observed even before the appearance of pathognomonic histopathological hallmarks of the disease [5]. Neurons are obligatorily dependent on mitochondrial energy production, which sustains a myriad of functions, including membrane remodeling, synaptic spine formation, and the generation of transmembrane resting and action potentials [6,7].

Mitochondria also play a pivotal role in cell survival and death by regulating apoptotic pathways and contributing to different cellular functions including intracellular calcium 
homeostasis, maintenance of the cellular redox potential, and cell cycle regulation. Recent evidence demonstrated that mitochondria are also important in regulating cell fate towards stemness or neurogenesis [8].

Thus, it is not surprising that mitochondrial dysfunction can have devastating effects on neuronal differentiation and survival. The brain is a major target in primary, genetically determined mitochondrial disease, but mitochondrial dysfunction is also a prominent feature in many of the most prevalent neurodegenerative diseases, including Parkinson's Disease (PD) [9], Huntington's Disease [10], neurodegeneration associated with stroke [11], Amyotrophic Lateral Sclerosis [12], neurodegenerative ataxias [13] and different types of psychiatric and cognitive disorders such as Dementia with Lewy Bodies [14], Frontotemporal Dementia [15], and Alzheimer's disease (AD) [16]. In AD, for example, the "mitochondrial cascade" hypothesis proposes that organellar dysfunction is the primary event in $\mathrm{AD}$ pathology [17]. Moreover, although the extracellular deposition of amyloid-beta $(A \beta)$ peptides $\left(A \beta_{1-40}, A \beta_{1-42}\right)$ is the key histopathological hallmark of $\mathrm{AD}, \mathrm{A} \beta$ accumulation is proposed to also occur in mitochondria, through the mitochondrial import machinery $[18,19]$, causing impairment of different mitochondrial pathways such as respiration, reactive oxygen species (ROS) detoxification, and organelle morphology [20-26].

The protease-mediated quality control system is a first-line homeostatic defense against mitochondrial damage, and includes degradation of non-assembled, misfolded or damaged proteins as a result of oxidative stress, elimination of cleaved products during protein processing, and overall regulation of protein turnover and homeostasis (referred to as proteostasis) [27]. The proteolytic system in mitochondria is crucial for the maintenance of protein turnover and the integrity of mitochondria. The majority of mitochondrial proteins are synthesized on cytosolic ribosomes with an $\mathrm{N}$-terminal peptide (the presequence or mitochondrial targeting sequence-MTS) which is recognized by-and binds to-specific receptors in the mitochondrial outer membrane. Following this event, these precursor mitochondrial proteins are translocated through the mitochondrial entry gate, the TOM (Translocase of Outer Membrane) complex and then, via a specific TIM (Translocase of Inner Membrane) system, TIM23, into the matrix [28], where they undergo proteolytic processes, including the cleavage of MTS, and structural modifications that lead to mature, functional proteins [29].

Several proteases and peptidases have been identified in different mitochondrial sub compartments. Most are ATP dependent proteases, such as the matrix-located Lon protease 1 (LONP1) and the membrane-bound AAA (ATPases Associated with diverse cellular Activities) proteases. The latter include i-AAA (Yme1), active in the intermembrane space (IMS), and m-AAA (Yta10/Yta12), exposed to the matrix. These enzymes catalyse the initial step of degradation, cleaving proteins into peptides, thus contributing to mitochondrial quality control [30]. Other ATP-independent proteases such as the mitochondrial processing peptidase (MPP), the mitochondrial intermediate protease (MIP), and the inner membrane peptidase (IMP), also generate short peptides. Upon import of the mitochondrial precursor proteins, MPP in the matrix cleaves the MTSs, releasing the mature proteins [31-33]. MPP activity can produce import intermediates, which are further processed by MIP (the octapeptidyl peptidase Oct1 in yeast) or IMP (the intermediate cleaving peptidase Icp55 in yeast) [33-36]. Therefore, all these proteases are involved in the processing of precursor protein and release free MTS peptides after proteolytic cleavage (Figure 1) [37].

Typically, the MTSs are amphiphilic species, with a polar, positively charged, argininerich side, opposite to an apolar side (Figure 1). Therefore, if these MTS peptides fail to be cleared from the mitochondrial matrix, they may act as detergent-like, toxic agents, forming pores in the membranes and resulting in uncoupling of oxidative phosphorylation and dissipation of the mitochondrial membrane potential [36]. 

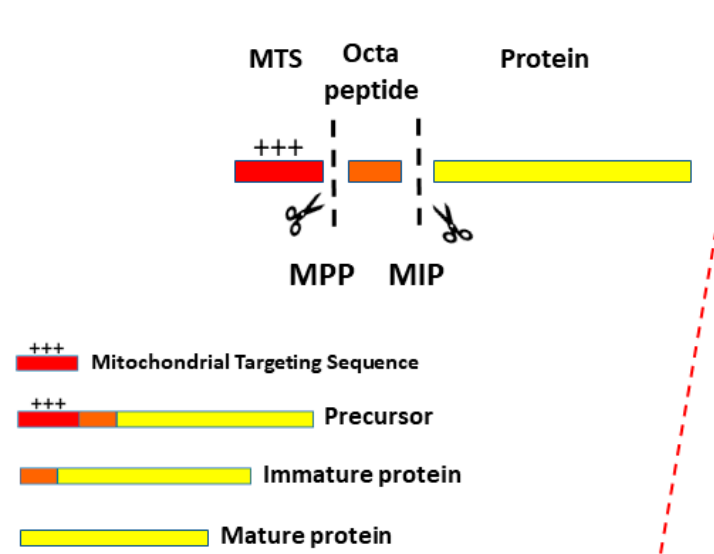

Mitochondrial Processing

Peptidase

MPP

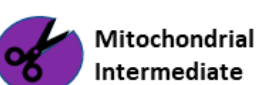

Intermediate

Peptidase
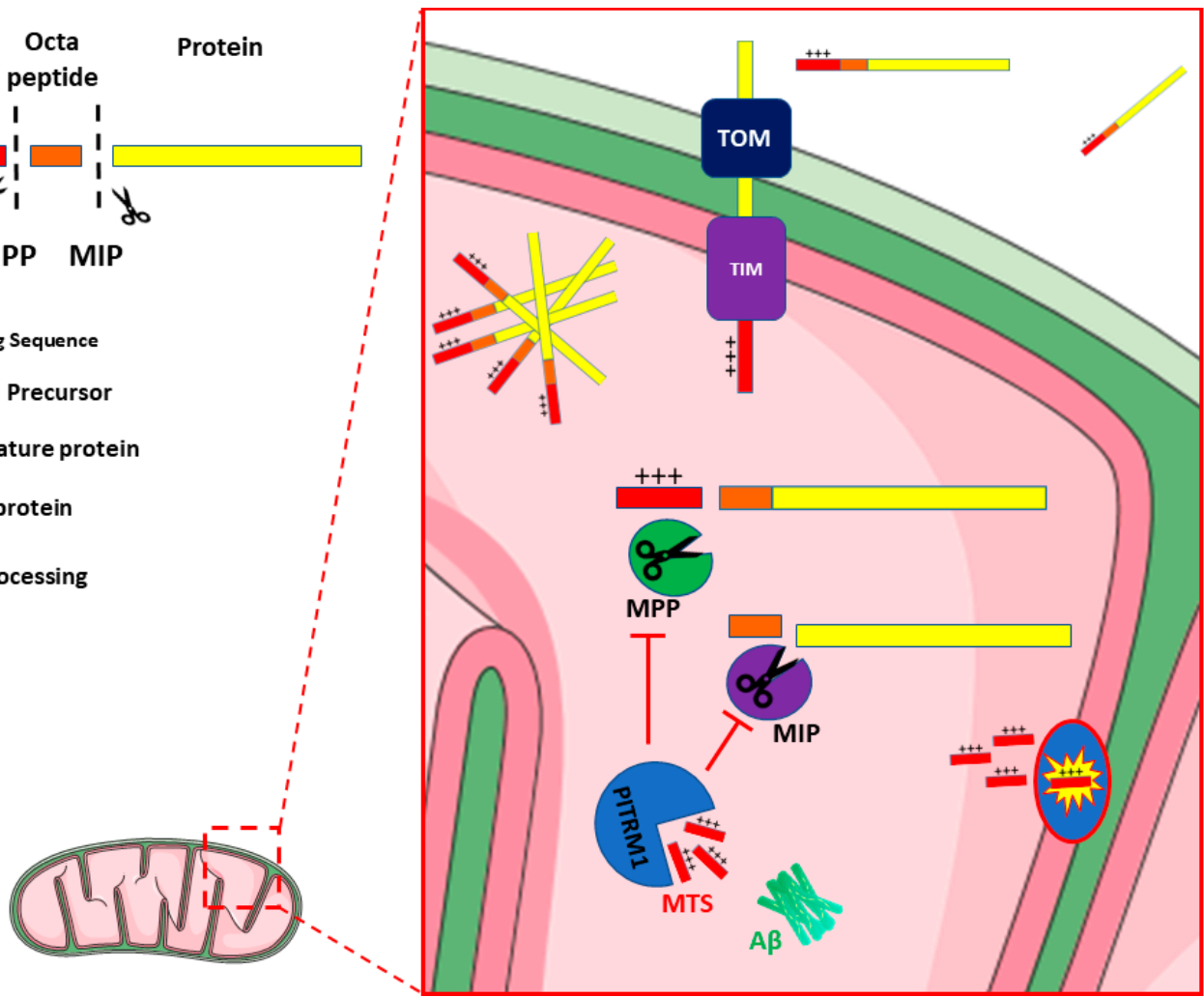

Figure 1. Schematic representation of PITRM1 function and interaction. Mitochondrial Precursor proteins are imported from cytosol to the matrix through the Translocase of the Outer Membrane (TOM) and Translocase of the Inner Membrane (TIM) complexes. Dysfunctional activity of PITRM1 results in the accumulation of Amyloid beta (A $\beta$ ), of Mitochondrial Targeting Sequences (MTS) and of octapeptides that trigger feedback inhibition of Mitochondrial Processing Peptidase (MPP) and Mitochondrial Intermediate Peptidase (MIP), leading to the accumulation and aggregation of unprocessed precursor. Figure 1 was modified from SMART (Servier Medical Art), licensed under a Creative Common Attribution 3.0 Generic License. http:/ / smart.servier.com/.

\section{PITRM1/PreP}

PITRM1, also termed Presequence protease (PreP), is localized in the mitochondrial matrix; it is the only known protein responsible for the degradation of the MTS, thus completing the last step of the protein import process. PreP was initially identified in Arabidopsis thaliana (AtPreP), and shown to degrade the MTS of both mitochondria and chloroplasts [38]. A yeast mutant lacking the PITRM1 homolog Cym1 [39] displayed mitochondrial accumulation of precursor proteins and processing intermediates, as well as decreased levels of cleaved, mature proteins [32,40]. Impaired preprotein maturation leads to accelerated protein degradation and an unbalanced mitochondrial proteome, resulting in mitochondrial dysfunction manifested by reduced respiration, altered membrane potential, and high ROS levels [28,37].

The human gene PITRM1 is located in chromosomal region 10p15.2, contains 27 exons, and is transcribed from the antisense strand. Three different isoforms of the protein correspond to transcript variants derived from alternative splicing. In isoforms 1 and 2, all 27 exons of the gene are retained and translated, with a total of 1038 and 1037 aminoacids (aa), respectively, due to the use of two different splice donor sites at exon 17 . The third isoform is the smallest one and contains 939 aa derived from 24 exons of the gene.

Human PITRM1 was initially identified as metalloprotease 1 [41], and shows $31 \%$ sequence identity to AtPreP, performing a similar function in human mitochondria. PITRM1 belongs to the M16 metalloproteases family, which are $\mathrm{Zn}^{2+}$-dependent and ATP-independent enzymes that share a conserved architecture of two $\sim 50 \mathrm{kDa}$ homologous domains enclos- 
ing a large catalytic chamber. Three families, M16-A, -B and -C, have been characterized depending on the connection between these two domains [42]. PITRM1 is a $117 \mathrm{kDa}$ M16C enzyme arranged in four domains, forming two enzyme halves, hPreP-N (amino acids 33-509) and hPreP-C (aa 576-1037) domains, connected by a hinge region (aa 510-575), which is possibly involved in the opening and closing of the two enzyme halves. Active site residues are located in both halves, which interact to form a large peptidasome chamber [43]. In addition to targeting peptides generated during the import processing, the large catalytic chamber of PITRM1 is also able to degrade a wide range of unstructured peptides, ranging from 10 to 65 aa, but not larger folded proteins [44].

In vitro studies demonstrated that human PITRM1 can degrade $A \beta_{1-40}, A \beta_{1-42}$ and the $A \beta$ arctic $\left(A \beta_{1-40} E 22 G\right)$, a peptide that causes increased fibril formation and early onset of a familial variant of AD. Its proteolytic activity generates several fragments, which are unique to PITRM1 (in comparison to other proteases), and recognizes the cleavage sites in the very hydrophobic C-terminal portion of $A \beta$ that is prone to aggregation [38]. Interestingly, the 3D structures of PITRM1 are highly similar to IDE (Insulin degrading enzyme), a zinc metallopeptidase that degrades intracellular insulin, as well as glucagon, amylin, beta-amyloid, bradykinin, and kallidin. Moreover, IDE has been suggested to have a role in the degradation of cleaved MTSs $[37,45]$. The preferential affinity of this enzyme for insulin results in the insulin-mediated inhibition of degradation of other peptides, such as beta-amyloid [46]. Variants in the IDE gene and deficiencies in the protein function have previously been associated with type 2 diabetes mellitus and Alzheimer's disease [47,48].

\section{PITRM1/PreP and Alzheimer's Disease}

\subsection{PITRM1/PreP Is Downregulated in AD Patients and Mouse Models}

It was reported that mitochondria isolated from the temporal lobe, an area of the brain that is highly susceptible to A $\beta$ accumulation, showed significantly lower PITRM1 activity in AD patients compared to age-matched control samples. In contrast, activity in mitochondria isolated from the cerebellum showed no differences [49]. Decreased expression of a transcript antisense to PITRM1 was found in the posterior cingulate cortex extracted from AD patients, suggesting changes in the regulation of PITRM1 expression [50].

Further, global proteomic studies revealed a mitochondrial proteome imbalance in AD samples, with presequence-containing mitochondrial proteins being particularly affected [23,51]. Similar experiments were performed in transgenic ( $\mathrm{Tg}$ ) mouse models of AD, including a Tg for APP (Amyloid- $\beta$ Protein Precursor), which is the most studied AD model, and ABAD (A $\beta$-binding alcohol dehydrogenase), which is an accelerated AD model. Indeed, $A \beta$ peptides are produced by regulated proteolysis of the APP through the action of $\beta$ - and $\gamma$ - secretases. ABAD or HSD17B10 interacts with A $\beta$ and mediates its mitochondrial toxicity [20]. The proteolytic activity of mouse PreP (mPreP) was significantly reduced in the matrix of cortical mitochondria isolated from 5-month-old Tg mAPP mice compared to non-Tg littermates. Similarly, the mPreP activity in Tg mAPP/ABAD mice was significantly lower than that in both non-Tg mice and Tg mA $\beta P P$ mice [49]. Transgenic mice overexpressing APP also showed lower mPreP proteolytic activity compared to age-matched, non-transgenic mice and a progressive, age dependent reduction in the same activity [49].

These results suggest that the loss of PITRM1 activity may result not only in the accumulation of $A \beta$, but also of free presequence peptides [36]. While the relevance of $A \beta$ accumulation still remains to be determined, the accumulation of presequence peptides is likely to be toxic.

The lower PITRM1 activity observed in AD brain mitochondria appears not to be due to lowered protein levels but to a functional alteration of the enzyme, possibly through posttranslational modifications such as protein oxidation. Oxidative stress is well-documented in AD brains and confirmed by the increase in several reactive oxygen species (ROS) markers [52]. For example, levels of 4-hydroxynonenal derived from lipid peroxidation, a biomarker of oxidation, were found to be higher in the temporal lobe of AD patients 
than controls, while were unchanged in the cerebellum [49]. These results suggest that lower temporal lobe PITRM1 activity reflects protein oxidation, and this is confirmed by several biochemical analyses using purified PITRM1 [53]. In addition, it has been shown that PITRM1 can be inactivated by the oxidative-dependent formation of disulfide bridges [43], which can be reverted by the antioxidant enzyme methionine sulfoxide reductase $\mathrm{A}(\mathrm{Msr} \mathrm{A})$ [53].

Interestingly, it appears that PITRM1 activity is not only important for degrading mitochondrial $A \beta$; it also appears to influence total brain $A \beta$ levels, suggesting that mitochondrial $A \beta$ somehow plays an important overall regulatory role. Since exogenous or intra-cellular $A \beta$ can enter mitochondria via the aforementioned pathways, the mitochondrial pool of $A \beta$ may undergo dynamic changes, contributing to the balance of intra-cellular/extra-cellular $\mathrm{A} \beta$ accumulation.

Increased neuronal $\mathrm{mPreP}$ in double transgenic $m A P P /$ PreP mice not only reduced $\mathrm{A} \beta$ accumulation in the brain but also remarkably suppressed the expression of the Receptor for Advanced Glycation End-products (RAGE) as compared with mutant APP mice. RAGE are important cell-surface receptor-mediating chemotactic and inflammatory reactions that occur in response to $\mathrm{A} \beta$ and other proinflammatory ligands [54,55]. RAGE signalling is known to promote the activation of microglia (as shown by increased expression of microglial markers e.g., CD4 and CD11) in the A $\beta$-enriched brain, and the production of proinflammatory mediators including cytokines and chemokines. These results suggest the involvement of RAGE in PreP/A $\beta$-mediated cytokine and chemokine production along with microglial activation [56].

\subsection{Targeting PITRM1/PreP as a New Therapeutic Strategy for Treatment of AD}

Besides AD patients, reduced levels of mPreP were found in both the hippocampus and cortex of the APPswe/PS1dE9 (APP/PS1) transgenic mouse, an AD model that develops spatial memory impairment, increased $A \beta$ deposition in the brain, synaptic loss, and mitochondrial dysfunction, features that are similar to those observed in AD patients. Importantly, 12 weeks of treatment with Ligustilide (LIG, 3-butylidene-4, 5-dihydrophthalide) in 7 month old APP/PS1 mice increased PreP protein levels and reduced mitochondrial $\mathrm{A} \beta_{1-42}$ concentration in both the hippocampus and neocortex [57]. Recently, an agedependent decrease in mPreP levels was reported by our group [58] in the hippocampus of the Senescence Accelerated Mouse Prone 8 (SAMP8), a model characterized by high oxidative stress and cognitive decline, with the onset of an AD-like phenotype between 9 and 15 months of age. Stimulation of the Sirt1-PGC-1 $\alpha$ axis by a metabolic activator increased mPreP protein levels and improved the cognitive dysfunction [59].

A potential role for PITRM1 in AD is also fostered by studies showing that increased expression and activity of neuronal $\mathrm{mPreP}$ significantly reduced the mitochondrial $\mathrm{A} \beta$ load, and improved mitochondrial function, and synaptic plasticity and strength, in AD mouse models, and prevented the development of impaired spatial learning and memory. This enhancement of PITRM1 activity provided a new therapeutic option for the treatment of AD [56,60]. Accordingly, there has been an increasing interest in the resolution of PITRM1 structure to develop specific agonists; benzimidazole derivatives (3c and 4c) were reported to act as agonists that boost PITRM1 proteolytic activity [61]. Unfortunately, pharmacological attempts using this approach have, so far, been unsuccessful [62] and therapeutic modulators of PITRM1 remain to be identified.

\section{Genetic Variants in Human PITRM1}

Perturbation of PITRM1 activity appears to influence A $\beta$ accumulation, making PITRM1 a candidate for diseases such as AD in which amyloid accumulates [43]. Nevertheless, a conclusive association between PITRM1 variants and AD has not yet been demonstrated [63]. In a genome-wide association study using microarray technology, 18 single nucleotide polymorphisms (SNPs) were found and genotyped in 673 AD cases and 649 controls in a Swedish population. AD cases comprised 256 unrelated familial AD 
subjects, having at least one affected first- or second-degree relative but no mutation detected in the APP, PS1 or PS2 genes, and 417 late onset clinical AD cases without a positive family history. No significant difference in genotype distribution between cases and controls, and no correlation between these mutations and AD progression could be identified. The SNPs analysed included nine tagged SNPs selected from the CEPH European panel in the Hapmap database with a minor allele frequency $>0.20$, and eight additional coding SNPs located in exon 4, which encodes the PITRM1 active site. However, a functional analysis of several PITRM1 SNP variants, selected on the basis of localization of the substituted amino acid in the enzyme structure, showed decreased activity in comparison to wild type PITRM1 [64].

\section{Biallelic Mutations in PITRM1 Are Associated with Complex Phenotypes and Amyloidotic Neurodegeneration}

We recently found that recessive PITRM1 mutations are associated with a slowly progressive syndrome characterized by mental retardation, spinocerebellar ataxia, cognitive decline and psychosis [65]. The first family described comes from a small Norwegian coastal community comprising $<200$ individuals. Out of five siblings, two were unquestionably affected, one additional sibling had peripheral neuropathy, another had psychiatric symptoms but refused investigation, and one died of cancer before DNA collection.

The index case (II-2) was diagnosed with mild intellectual disability as a child and later developed progressive spinocerebellar ataxia, obsessional behaviour and psychotic episodes with hallucinations. Brain MRI showed marked cerebellar atrophy and unilateral signal changes in the thalamus. The routine blood profile was unremarkable, but cerebrospinal fluid (CSF) examination showed low levels of $A \beta_{1-42}$ (363 ng/L; n.v. > 550), similar to the ones detected in idiopathic AD $[66,67]$. Total and phosphorylated Tau and 14-3-3 proteins were normal. A muscle biopsy showed some scattered COX-negative fibres. Respiratory chain (RC) complex assays in muscle homogenate from individual II-2 showed low specific activities of all RC complexes, with a concomitant decrease in citrate synthase (CS), an index of mitochondrial mass. Her brother (II-4) was reported to be mildly mentally retarded from an early age, and also developed obsessional behaviour with episodes of psychosis, and early onset ataxia. His CT scan showed cerebellar and milder cerebral atrophy.

SNP-based homozygosity mapping and whole exome sequencing (WES) revealed a c.548G > A p.R183Q mutation in PITRM1. The PITRM1 ${ }^{R 183 Q}$ mutation resulted in a marked reduction in PITRM1 protein levels in patients' fibroblasts and skeletal muscle cells. In vitro, its catalytic activity was comparable to wild-type protein. However, when modelled in yeast, the R183Q substitution resulted in lower mitochondrial oxygen consumption and cytochrome content and reduced capacity to degrade A $\beta$. A recent study [68] showed that the structural and electrostatic properties of the conserved strand-loop-strand motif containing PITRM1 residue R183 are critically important for PITRM1 function. The mutational disruption of electrostatic interactions in proximity of PITRM1 residue R183 contributes to the loss of enzyme activity and may contribute to the loss-of-function phenotype observed in PITRM1 R183Q-dependent neuropathy. However, PITRM1 activity was not tested directly, but deduced in vitro using the recombinant protein and fluorogenic substrates rather than native presequence peptides.

A novel PITRM1 mutation causing autosomal recessive spinocerebellar ataxias (ARCA) in four children from two independent families was recently identified in Jerusalem, Israel [69]. Affected patients from both families were born to consanguineous parents and the onset of the disease was in early childhood. Even though they carried the same PITRM1 variant (PITRM1T931M) on a shared genetic haplotype, they showed a significantly different phenotype. This is likely attributable to an additional chromosome $\mathrm{X}$ rearrangement found in the first family; indeed, homozygous brothers belonging to this pedigree presented with a more severe disease course characterized by delayed psychomotor development, severe ataxia and psychotic episodes, somehow resembling the Norwegian family above mentioned. Brain MRI revealed cerebellar atrophy, while signs of muscle involvement 
(elevated plasma CPK and lactate/pyruvate) were detected in one of them. A milder psychomotor retardation was reported in both siblings from the second Palestinian family, with one subject also presenting with cerebellar signs. Both patients from this second family had normal MRI and routine blood tests.

Again, functional studies performed on patients' fibroblasts transduced with the recombinant wild-type protein, and, in a yeast model, demonstrated that this mutation leads to loss of function shown by a defective cleavage of $>40$ amino acid peptides, including $\mathrm{A} \beta$ species, strengthening the connection between impairment of mitochondrial peptide degradation and neurodegenerative diseases [69].

A very recent case report described a new patient harboring a homozygous variant, c.2239dupG, in PITRM1 due to segmental maternal isodisomy of chromosome 10. The patient presented at 25 months of age with seizures, hypotonia and delayed motor and language development. At 36 months of age, the patient evidenced a severe ataxic syndrome associated with intellectual disability and persistence of epilepsy. Unlike previously reported cases, this patient did not show any psychiatric symptoms until the last follow up examination (at 6 years). Besides a moderate cerebellar atrophy, brain MRI also revealed bilateral thalamic hyperintensity.

The patient's fibroblasts had severely reduced PITRM1 transcript and protein expression, and the measurement of oxygen consumption rates denoted impaired mitochondrial ATP metabolism due to defective OXPHOS [70].

Thus, robust evidence shows that PITRM1 deficiency due to biallelic variants leads to progressive neurological impairment including ataxia, mental retardation and psychiatric features, and an overall susceptibility to neurodegeneration (Table 1). 
Table 1. Summary of clinical findings in patients harboring biallelic mutations in PITRM1.

\begin{tabular}{|c|c|c|c|c|c|c|c|}
\hline & Patient 1 [65] & Patient 2 [65] & Patient 3 [69] & Patient 4 [69] & Patient 5 [69] & Patient 6 [69] & Patient 7 [70] \\
\hline PITRM1 variant & c. $548 \mathrm{G}>\mathrm{A}$ & c. $548 \mathrm{G}>\mathrm{A}$ & c. $2795 \mathrm{C}>\mathrm{T}$ & c. $2795 \mathrm{C}>\mathrm{T}$ & c. $2795 \mathrm{C}>\mathrm{T}$ & c. $2795 \mathrm{C}>\mathrm{T}$ & c.2239dupG \\
\hline $\begin{array}{l}\text { Effect on PITRM1 } \\
\text { expression }\end{array}$ & Markedly reduced & Markedly reduced & Markedly reduced & Markedly reduced & Markedly reduced & Markedly reduced & Markedly reduced \\
\hline Ethnicity & Norwegian & Norwegian & Palestinian Arab & Palestinian Arab & Palestinian Arab & Palestinian Arab & Unknown \\
\hline Onset of disease & Childhood & Childhood & 5 months & Early childhood & 2 years & Early childhood & 25 months \\
\hline Symptoms at onset & $\begin{array}{l}\text { Mild intellectual } \\
\text { disability }\end{array}$ & Mental retardation & $\begin{array}{l}\text { Developmental delay, } \\
\text { tremor }\end{array}$ & Developmental delay & $\begin{array}{l}\text { Mild motor and } \\
\text { cognitive } \\
\text { impairment, } \\
\text { dysmetria }\end{array}$ & $\begin{array}{l}\text { Mild motor and } \\
\text { speech delay }\end{array}$ & $\begin{array}{c}\text { Seizures, } \\
\text { developmental delay, } \\
\text { hypotonia }\end{array}$ \\
\hline $\begin{array}{l}\text { Main clinical } \\
\text { findings }\end{array}$ & $\begin{array}{l}\text { Ataxic syndrome, } \\
\text { cognitive } \\
\text { impairment, } \\
\text { psychosis }\end{array}$ & $\begin{array}{l}\text { Ataxic syndrome, } \\
\text { cognitive } \\
\text { impairment, } \\
\text { psychosis }\end{array}$ & $\begin{array}{l}\text { Intellectual disability, } \\
\text { severe ataxic } \\
\text { syndrome, psychosis }\end{array}$ & $\begin{array}{c}\text { Moderate intellectual } \\
\text { disability, severe } \\
\text { ataxic syndrome, } \\
\text { psychosis }\end{array}$ & $\begin{array}{l}\text { Mild developmental } \\
\text { delay and ataxic } \\
\text { syndrome }\end{array}$ & $\begin{array}{l}\text { Mild developmental } \\
\text { delay }\end{array}$ & $\begin{array}{c}\text { Ataxic syndrome, } \\
\text { intellectual disability }\end{array}$ \\
\hline Brain Imaging & $\begin{array}{c}\text { Marked cerebellar } \\
\text { atrophy, unilateral } \\
\text { thalamic signal } \\
\text { changes }\end{array}$ & $\begin{array}{l}\text { Cerebellar and mild } \\
\text { cerebral atrophy }\end{array}$ & Cerebellar atrophy & $\begin{array}{l}\text { Severe cerebellar } \\
\text { atrophy, mild } \\
\text { cerebral atrophy }\end{array}$ & Normal & Normal & $\begin{array}{c}\text { Moderate cerebellar } \\
\text { atrophy, bilateral } \\
\text { thalamic signal } \\
\text { changes }\end{array}$ \\
\hline Muscle biopsy & COX-negative fibers & Unknown & Normal & Unknown & Unknown & Unknown & $\begin{array}{l}\text { Slight mitochondrial } \\
\text { proliferation }\end{array}$ \\
\hline $\begin{array}{l}\text { OXPHOS efficiency } \\
\text { on patients' } \\
\text { fibroblasts }\end{array}$ & Unknown & Unknown & Unknown & Unknown & Unknown & Unknown & Defective \\
\hline Other findings & $\begin{array}{c}\text { Low } \mathrm{A} \beta_{1-42} \mathrm{CSF} \\
\text { levels }\end{array}$ & n.r. & $\begin{array}{l}\text { Increased levels of } \\
\text { CPK, lactate and } \\
\text { pyruvate on blood } \\
\text { tests }\end{array}$ & $\begin{array}{l}\text { No sign of muscle } \\
\text { damage on blood } \\
\text { tests }\end{array}$ & $\begin{array}{l}\text { No sign of muscle } \\
\text { damage on blood } \\
\text { tests }\end{array}$ & $\begin{array}{l}\text { No sign of muscle } \\
\text { damage on blood } \\
\text { tests }\end{array}$ & n.r. \\
\hline
\end{tabular}

A $\beta_{1-42}$ : amyloid beta 1-42; COX: cytochrome c oxidase; CPK: creatine phosphokinase; CSF: Cerebrospinal fluid; n.r.: not reported. 


\section{Animal Models with Genetic PITRM1 Impairment}

\subsection{Mouse Models}

A Pitrm1 knock-out C57BL/6n-Atm1Brd mouse model was developed by the Wellcome Trust Sanger Institute, Cambridge, UK, and first described by our group [65]. Whilst the constitutive Pitrm $1^{-/-}$genotype is associated with embryonic lethality, Pitrm $1^{+/-}$ heterozygotes survived to adulthood and reduced the levels of Pitrm1 protein in different tissues (50\% in brain and liver, and approximately $60 \%$ in skeletal muscle), thus replicating the haploinsufficiency-like effect of PITRM1 ${ }^{\text {R183Q }}$ patients (reduced amount of a catalytically normal enzyme).

Pitrm $1^{+/-}$mice present with an early onset, slowly progressive neurological phenotype starting with a clasping reflex and evolving into an ataxic phenotype with reduced performance in coordination tests. Metabolic assessment showed significantly reduced $\mathrm{O}_{2}$ consumption and $\mathrm{CO}_{2}$ production, and reduced heat production. Western blot immune analysis on 4-month old (mo) brain homogenates revealed an approximately 2.5-fold increase in APP cross-reacting material in Pitrm $^{+/-}$vs. Pitrm $1^{+/+}$specimens. Neuropathological analysis of 4-12 mo mice revealed increased gliosis, accumulation of ubiquitinpositive material in the neuropil and neurons, and increased reactivity to APP and A $\beta_{1-42}$ antibodies. Furthermore, scattered Thioflavin and Congo red-positive areas were found in the brain cortex, indicating the presence of amyloid deposits. The import of $A \beta_{1-42}$ into isolated mitochondria was studied in $\mathrm{Pitrm}^{1^{+/+}}$and $\mathrm{Pitrm}^{+/-}$mice and confirmed a reduced capacity of Pitrm $1^{+/-}$brain and liver mitochondria to degrade $\mathrm{A} \beta_{1-42}$, causing this peptide to accumulate. Using in-vitro import experiments, we also demonstrated an accumulation of MTS in Pitrm $1^{+/-}$mitochondria.

In a previously published paper [65], we described the clinical phenotype observed in the mouse during the first 12 months of age. The evolution of symptoms for up to 24 months (unpublished data) included hind limb paresis and tremors at the age of 15 months, and significant cognitive deficit at the $\mathrm{Y}$ maze after 12 months of age (unpublished data). These findings suggest that not only recessive homozygous mutations (as in the PITRM1 families), but also haploinsufficiency associated with monoallelic heterozygous variants, are associated with increased susceptibility to adult-onset neurodegeneration.

\subsection{A PITRM1 Mutant Dog}

A novel early-onset PITRM1-related neurodegenerative syndrome was recently described in Parson Russell Terrier dogs [71]. The disease started with epilepsy at 6-12 weeks of age, presenting seizures with orofacial automatism and twitching, repeated jerking head movements, rhythmic blinking, swallowing, salivation, and anxiety-related behaviour that progressed rapidly to status epilepticus and death or euthanasia. Neuropathological analysis revealed a severe acute neuronal degeneration with diffuse necrosis affecting the grey matter throughout the brain, with extensive intraneuronal mitochondrial crowding and accumulation of $A \beta$.

Genetic analysis identified an in-frame homozygous 6-bp deletion in PITRM1 resulting in the loss of two amino acid residues in the N-terminal part of the protein (predicted as p.L59_S60del or, alternatively, p.S60_L61del). Bioinformatics analysis predicted that the deletion affected a region where the three-dimensional protein structure forms a short helix followed by a $\beta$-strand and that loss of the amino acids would be deleterious. Immunohistochemistry in different tissues revealed similar levels of PITRM1 protein, suggesting that structural changes potentially affected the catalytic activity necessary for precursor processing and degradation. Modelling the change in yeast confirmed the deleterious nature of the mutation, showing a $20 \%$ reduction in the catalytic activity. In contrast to the mouse model, heterozygous dogs were normal.

Lastly, a separate study on dogs affected by progressive retinal atrophy (PRA), the equivalent of retinitis pigmentosa (RP) in humans, revealed that nonsynonymous coding SNPs in PITRM1 (p.S715A) and APP (p.T266M) were significantly associated with this type of neurodegeneration [72]. 


\section{Cellular Models of PITRM1 Impairment}

Fibroblasts derived from a Norwegian patient carrying the PITRM1 $1^{R 183 Q}$ mutation were the first in vitro model used to characterize cellular pathophysiology associated with PITRM1 dysfunction. Evidence of mitochondrial dysfunction in this cell line includes a significant growth defect observed on respiration-obligatory galactose medium, but not on glycolytic-permissive glucose medium, compared to PITRM1 ${ }^{\text {wt }}$ cells. A similar growth defect was observed in control immortalised fibroblasts stably expressing a PITRM1-specific shRNA, which decreased PITRM1 protein levels to approximately $40 \%$ of the amount found in cells transfected with the empty vector. All these cell lines also showed a significant reduction in the mitochondrial membrane potential and a reduced disposal of a synthetic, exogenous fluorescent $A \beta_{1-40}$ peptide. The same findings have been observed in the PITRM1 ${ }^{\text {T931M }}$ mutant fibroblasts (data not published).

To study changes in mitochondrial physiology due to loss of PITRM1, a PITRM1 knockout HEK293T cell line (PreP ${ }^{-/-}$) was generated [37]. Loss of PITRM1 resulted in severe mitochondrial dysfunction characterized by defects in respiratory chain complexes and membrane potential. Complex III, complex IV, and respiratory chain supercomplexes (SC) were reduced in PITRM1-/- mitochondria compared to wild-type, while complex II was not altered. Basal and maximal respiration were significantly lower in PITRM1 ${ }^{-/-}$ compared to control and the mitochondrial membrane potential decreased, compromising the mitochondrial capacity to import newly synthesized precursor proteins from the cytosol. Further, cells lacking PITRM1 displayed changes in the nuclear expression of genes associated with mitochondrial stress responses (ATF4, CHAC1, ASNS, and PCK2), which activates retrograde signaling used by the cells to respond to mitochondrial dysfunction [73]. These are referred as mitochondrial stress responses and preserve cell viability by modulating metabolic and mitochondrial pathways [74].

Mechanistic analysis of PITRM1-/- cells demonstrated impaired MTS degradation. As a consequence, compromised presequence cleavage by MPP occurred, with accumulation of non-processed precursor proteins, revealing that presequence degradation is coupled with precursor processing that is similar to what was described in the Cym1 (orthologue of PITRM1) null yeast model [75]. Furthermore, the activity of MIP (a peptidase that cleaves eight residues from a subset of precursors) was strongly impaired in import assays on isolated mitochondria, suggesting that PITRM1 also degrades cleaved octapeptides and that their accumulation in the absence of PITRM1 induces feedback inhibition of MIP.

To overcome the limitation of the embryonic lethality previously observed in PITRM1knockout mice and examine the mechanistic link between PITRM1 deficiency and neurodegeneration in a model resembling human disease, PITRM1-knockout $\left(\right.$ PITRM1 $\left.{ }^{-/-}\right)$human induced pluripotent stem cells (iPSCs) were generated using CRISPR/Cas9 endonuclease [76]. This system introduced a frameshift deletion between exon 3 and exon 4 , which resulted in the complete absence of the protein.

The first functional evidence of mitochondrial impairment was provided by the decreased ratio of processed, mature to immature frataxin detected in PITRM1 ${ }^{-/}$iPSCderived neural precursor cells and neurons, confirming that the loss of PITRM1 leads to impaired function of MPP and defects in mitochondrial presequence processing, such as that of frataxin. Notably, a similar dysregulation of frataxin maturation was found in HEK293T cells, both in the PITRM1 ${ }^{-/-}$and in the PITRM1 ${ }^{R 183 Q}$ models [37]. However, whether frataxin processing and maturation are dysregulated in patients with mutated PITRM1 has not yet been clarified.

Loss of the mitochondrial membrane potential was more evident in the neurites than in the soma in PITRM1 ${ }^{-/-}$iPSC-derived neurons compared with isogenic PITRM1 ${ }^{+/+}$control.

Accumulation of damaged or unfolded proteins in mitochondria triggers a compensatory mechanism termed mitochondrial unfolded protein response (UPRmt) [73,77,78]. UPRmt gene activation was observed in both sporadic and familial AD [77,79]. PITRM1 deficiency also strongly induced UPRmt, and iPSC-derived neurons exhibited a significant upregulation of ATF4, DDIT3, HSP60, HSPA9, ERO1 transcripts as well as increased expres- 
sion levels of the mitochondrial proteases LONP1 and CLP. This strong upregulation of the integrated stress response (ISR) pathway [80], in turn, induced autophagy activation and increased mitochondrial clearance. Furthermore, PITRM1-knockout neurons showed higher levels of amyloid precursor protein and $A \beta$, albeit without an increase in cell death. Sub-fractionation methods coupled with a highly sensitive immunoassay failed, however, to detect $\mathrm{A} \beta$ peptides in mitochondrial extracts from iPSC-derived nerve cells, raising the question of whether these structures enter mitochondria, at least under these experimental conditions. This is in contrast with results previously reported by several groups, documenting the presence of $A \beta$ within mitochondria $[26,81,82]$.

Accumulation of APP and $A \beta_{1-40}$ peptide in cell cultures may indeed be attributed to protein backlogging in the cytoplasm caused by the accumulation of non-digested MTS, producing a general impairment of mitochondrial protein translocation and cell proteostasis. This mechanism could indeed explain the accumulation not only of APP and $A \beta_{1-40}$ peptides but also of other proteins including, for instance, TDP-43, FUS, and Tau. That this could be driven by defective PITRM1 is supported by our preliminary data showing a skewed distribution of a potentially deleterious heterozygous PITRM1 variant in a cohort of approximately 600 subjects with either AD or FTD and FTD-related clinical variants, compared to age-matched controls (unpublished data).

Another interesting finding in PITRM1 $1^{-/-}$neurons is the significant decrease in mitochondrial membrane potential that is more evident in neurites than in soma [74]. Assuming that this phenomenon is due to $A \beta$ accumulation, it would support previous observations documenting a more evident aggregation of $A \beta$ in synaptic mitochondria. However, PITRM1 ${ }^{-/-}$neurons did not show an increase in mitochondrial ROS production or defects in oxidative phosphorylation, which have been considered direct deleterious effects of $A \beta$ accumulation [76].

Importantly, cerebral organoids derived from PITRM1-deficient iPSCs did spontaneously develop $\mathrm{AD}$ pathological features including protein aggregates, tau pathology, and neuronal cell death. All of these features were exacerbated by treatment with ISRIB, a global integrated stress response (ISR) inhibitor [83,84]. ISRIB-treated PITRM1 ${ }^{+/+}$ cerebral organoids showed a significant increase in cleaved caspase-3-positive cells. Interestingly, ISRIB-treated cerebral organoids also showed an increase in mitochondrial DNA, suggesting that the inhibition of UPRmt leads to decreased mitochondrial clearance.

All the findings reviewed above suggest that PITRM1 deficiency induces an impairment of mitochondrial proteostasis and the activation of UPRmt, which, in turn, activates cytosolic quality control pathways such as the ubiquitin-proteasome system (UPS) and autophagy [85]. The overload of the UPS reduces the capacity to degrade cytosolic proteins, leading to APP accumulation, the rise of $A \beta$ species, an increased $A \beta 42 / 40$ ratio, and extracellular protein aggregation. Notably, boosting mitophagy via $\mathrm{NAD}^{+}$precursors partly prevented $A \beta$ proteotoxicity [86].

The effects of PITRM1 loss may also affect immune competence. While single-cell RNA sequencing showed impaired mitochondrial function in all cell types in PITRM1-knockout cerebral organoids, inflammatory pathways (including iNOS, PPAR signalling TNFR1, RAR activation, chemokine, and IL-17A signalling pathways) were significantly dysregulated in astrocytes. Furthermore, PITRM1 ${ }^{-1-}$ cerebral organoids showed a substantial increase in the inflammatory cytokine TNF- $\alpha$, which is consistent with a role of PITRM1 deficiency in immune pathways. Notably, increases in pro-inflammatory cytokines and the activation of adaptive immune response have been described in various neurodegenerative diseases [87]. For instance, AD patients showed altered plasma and CSF levels of pro-inflammatory IL- $1 \beta$, IL-6, and TNF- $\alpha$, as well as anti-inflammatory cytokines, IL-1 receptor antagonist, and IL-10 [88].

\section{Conclusions}

Mitochondrial protein homeostasis (proteostasis) is key for the maintenance of energetic efficiency and for protein quality control, and its impairment has been associated 
with human disease and neurodegeneration [89]. In this review, we collected substantial evidence suggesting that the mitochondrial peptidase PITRM1 plays an important role in cellular proteostasis. By processing the MTS of proteins transported into the inner compartment of mitochondria, PITRM1 prevents the accumulation of potentially toxic structures acting as detergents and, therefore, damaging the mitochondrial membranes. In addition, the role of PITRM1 is at the end of a chain of events, which include the cleavage of the MTS by the inner membrane peptidase, after the translocation of the precursor proteins by the TIM23 system, which acts in an energy-dependent fashion due to the exploitation of the mitochondrial membrane potential and the presence of ATP. Therefore, the block of PITRM1 digestion can determine the backlogging of proteins during their translocation into the inner compartment of mitochondria, and potentially the impairment not only of this crucial mechanism for mitochondrial homeostasis, but also the accumulation of mitochondrial protein precursors in the cytosol, eventually determining a general derangement of proteostasis in the cell. Although several reports indicate that APP and its abnormal digestion product $A \beta_{1-42}$ can accumulate within mitochondria, where it is disposed by PITRM1, the question is still controversial. Nevertheless, investigation in the recessive human PITRM1related disease as well as indifferent experimental models in vivo and in vitro show that impaired PITRM1 enzymatic activity can cause $A \beta$ accumulation, whether in mitochondria or in the cytosol, and damage to multiple mitochondrial pathways, eventually leading to MTS and misfolded protein accumulation, increased UPRmt, and possibly dysregulation of the inflammatory response. Impaired mitochondrial proteostasis could also trigger a cytosolic response with overload and saturation of the proteasome and defective cytosolic protein degradation, eventually increasing extracellular protein aggregation (Figure 2).

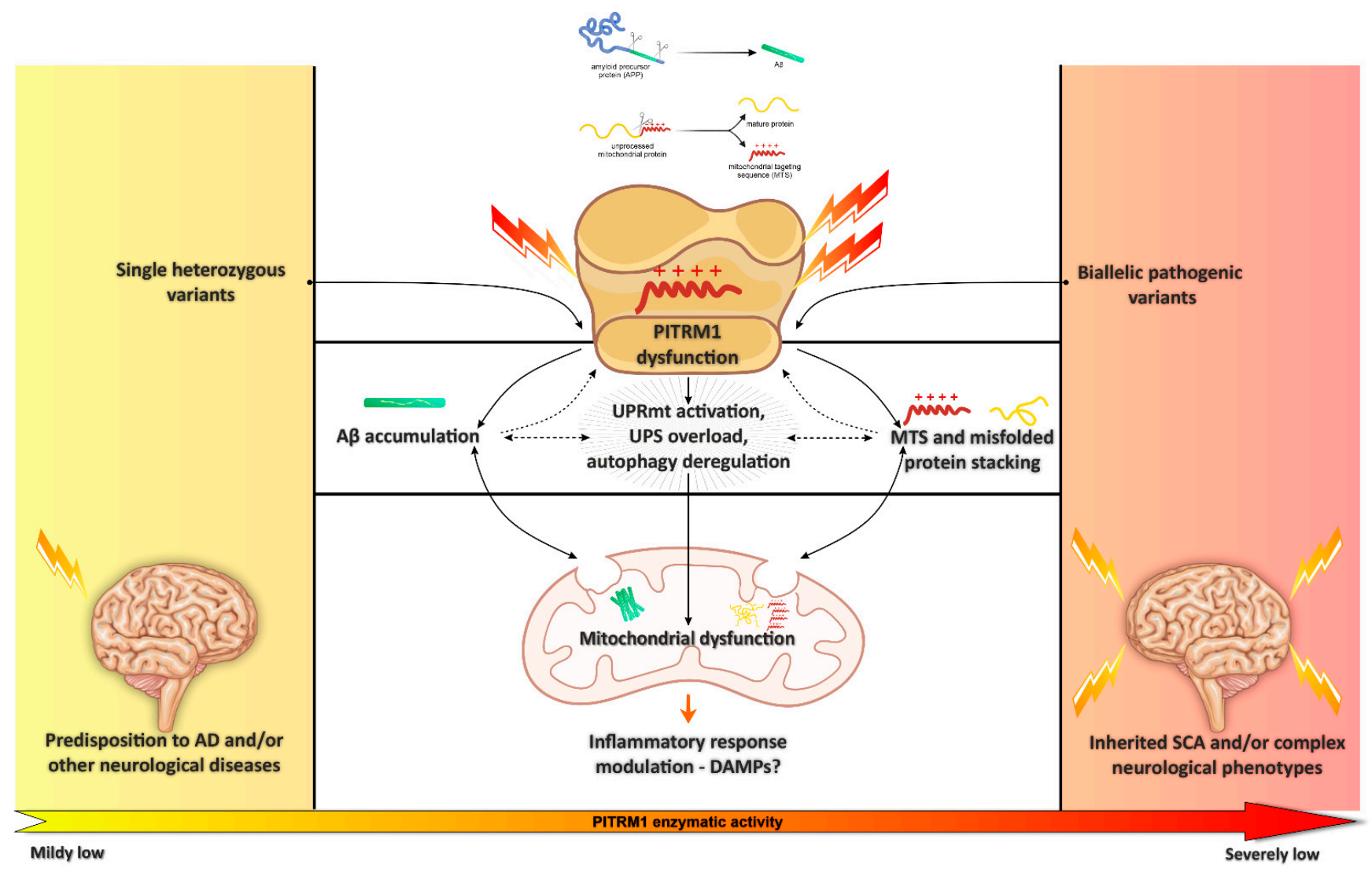

Figure 2. Schematic representation of the mitochondrial pathways associated with impaired PITRM1 enzymatic activity, mainly linked to Amyloid beta (A $\beta$ ) accumulation and mitochondrial targeting sequence (MTS) and misfolded protein stacking. Figure 2 was modified from SMART (Servier Medical Art), licensed under a Creative Common Attribution 3.0 Generic License. http:/ /smart.servier.com/. 
Future research directions will include the assessment of diagnostic markers (e.g., monitoring PITRM1 levels or measuring the concentration of precursor proteins in patients' blood cells) and the development of therapeutic approaches aimed to stimulate/preserve the presequence processing machinery. For the latter purpose, a possible strategy is based on the identification of new effective PITRM1 agonists through high-throughput screening or drug repurposing. An alternative option relies on the stimulation of IDE to compensate the reduced MTS degradation due to the PITRM1 deficit. Recent reports showed that the IDE promoter is a direct target of the Peroxisome proliferator-activated receptor gamma (PPAR $\gamma$ ) [90]; furthermore, inositol phosphates was shown to interact with the inner chamber wall of IDE, leading to a remarkable increase in the enzyme activity [91]. Finally, approaches aimed at stimulating mitochondrial biogenesis [92] could be used in cells/patients with partly deficient PITRM1 or haploinsufficiency, since they are expected to promote some improvement by increasing the number of functional units, and possibly of the PITRM1 activity. Moreover, we showed that enhancing UPRmt and mitophagy ameliorates neuropathological features in defective PITRM1 cells [76].

Although further studies are required to fully elucidate the pathogenic mechanism triggered by PITRM1, available data provide substantial support for its primary role in diverse mitochondrial dysfunctions associated with neurodegeneration.

Author Contributions: Writing—original draft preparation, D.B., A.C., D.G. and M.Z.; writingreview and editing, C.V., M.D. and L.A.B.; figure artwork: D.B. and A.C. All authors have read and agreed to the published version of the manuscript.

Funding: This research was funded by the University of Milan, grant SoE-SEED2020_MI.to.AD (to D.G. and D.B.), by the Foundation Telethon-Italy, grant GSP20003_PAsAtaxia002 (to D.B.), GGP19007 (to M.Z.) and GGP20013 (to C.V.) by the Telethon Foundation, Helmholtz Association Young Investigator Award (VH-NG-1123, to M.D.).

Conflicts of Interest: The authors declare no conflict of interest.

\section{References}

1. Morán, M.; Moreno-Lastres, D.; Marín-Buera, L.; Arenas, J.; Martín, M.A.; Ugalde, C. Mitochondrial Respiratory Chain Dysfunction: Implications in Neurodegeneration. Free. Radic. Biol. Med. 2012, 53, 595-609. [CrossRef] [PubMed]

2. Monzio Compagnoni, G.; Di Fonzo, A.; Corti, S.; Comi, G.P.; Bresolin, N.; Masliah, E. The Role of Mitochondria in Neurodegenerative Diseases: The Lesson from Alzheimer's Disease and Parkinson's Disease. Mol. Neurobiol. 2020, 57, 2959-2980. [CrossRef]

3. Wu, Y.; Chen, M.; Jiang, J. Mitochondrial Dysfunction in Neurodegenerative Diseases and Drug Targets via Apoptotic Signaling. Mitochondrion 2019, 49, 35-45. [CrossRef] [PubMed]

4. Tapias, V. Editorial: Mitochondrial Dysfunction and Neurodegeneration. Front. Neurosci. 2019, 13, 1372. [CrossRef]

5. Mosconi, L.; Pupi, A.; De Leon, M.J. Brain Glucose Hypometabolism and Oxidative Stress in Preclinical Alzheimer's Disease. Ann. N. Y. Acad. Sci. 2008, 1147, 180-195. [CrossRef]

6. Bifari, F.; Dolci, S.; Bottani, E.; Pino, A.; Di Chio, M.; Zorzin, S.; Ragni, M.; Zamfir, R.G.; Brunetti, D.; Bardelli, D.; et al. Complete Neural Stem Cell (NSC) Neuronal Differentiation Requires a Branched Chain Amino Acids-Induced Persistent Metabolic Shift towards Energy Metabolism. Pharmacol. Res. 2020, 158, 104863. [CrossRef] [PubMed]

7. Son, G.; Han, J. Roles of Mitochondria in Neuronal Development. BMB Rep. 2018, 51, 549-556. [CrossRef] [PubMed]

8. Inak, G.; Rybak-Wolf, A.; Lisowski, P.; Pentimalli, T.M.; Jüttner, R.; Glažar, P.; Uppal, K.; Bottani, E.; Brunetti, D.; Secker, C.; et al . Defective Metabolic Programming Impairs Early Neuronal Morphogenesis in Neural Cultures and an Organoid Model of Leigh Syndrome. Nat. Commun. 2021, 12, 1929. [CrossRef]

9. Winklhofer, K.F.; Haass, C. Mitochondrial Dysfunction in Parkinson's Disease. Biochim. Biophys. Acta (BBA)-Mol. Basis Dis. 2010, 1802, 29-44. [CrossRef]

10. Sharma, A.; Behl, T.; Sharma, L.; Aelya, L.; Bungau, S. Mitochondrial Dysfunction in Huntington's Disease: Pathogenesis and Therapeutic Opportunities. CDT 2021, 22. [CrossRef]

11. Carinci, M.; Vezzani, B.; Patergnani, S.; Ludewig, P.; Lessmann, K.; Magnus, T.; Casetta, I.; Pugliatti, M.; Pinton, P.; Giorgi, C. Different Roles of Mitochondria in Cell Death and Inflammation: Focusing on Mitochondrial Quality Control in Ischemic Stroke and Reperfusion. Biomedicines 2021, 9, 169. [CrossRef]

12. Mehta, A.R.; Gregory, J.M.; Dando, O.; Carter, R.N.; Burr, K.; Nanda, J.; Story, D.; McDade, K.; Smith, C.; Morton, N.M.; et al. Mitochondrial Bioenergetic Deficits in C9orf72 Amyotrophic Lateral Sclerosis Motor Neurons Cause Dysfunctional Axonal Homeostasis. Acta Neuropathol. 2021, 141, 257-279. [CrossRef] [PubMed] 
13. Gohel, D.; Berguerand, N.C.; Tassone, F.; Singh, R. The Emerging Molecular Mechanisms for Mitochondrial Dysfunctions in FXTAS. Biochim. Biophys. Acta (BBA)-Mol. Basis Dis. 2020, 1866, 165918. [CrossRef] [PubMed]

14. Spano, M. The Possible Involvement of Mitochondrial Dysfunctions in Lewy Body Dementia: A Systematic Review. Funct. Neurol. 2015, 30, 151-158. [CrossRef] [PubMed]

15. Huang, C.; Yan, S.; Zhang, Z. Maintaining the Balance of TDP-43, Mitochondria, and Autophagy: A Promising Therapeutic Strategy for Neurodegenerative Diseases. Transl. Neurodegener. 2020, 9, 40. [CrossRef]

16. Moreira, P.I.; Carvalho, C.; Zhu, X.; Smith, M.A.; Perry, G. Mitochondrial Dysfunction Is a Trigger of Alzheimer's Disease Pathophysiology. Biochim. Biophys. Acta (BBA)-Mol. Basis Dis. 2010, 1802, 2-10. [CrossRef]

17. Swerdlow, R.H. Mitochondria and Mitochondrial Cascades in Alzheimer's Disease. JAD 2018, 62, 1403-1416. [CrossRef]

18. Hansson Petersen, C.A.; Alikhani, N.; Behbahani, H.; Wiehager, B.; Pavlov, P.F.; Alafuzoff, I.; Leinonen, V.; Ito, A.; Winblad, B.; Glaser, E.; et al. The Amyloid -Peptide Is Imported into Mitochondria via the TOM Import Machinery and Localized to Mitochondrial Cristae. Proc. Natl. Acad. Sci. USA 2008, 105, 13145-13150. [CrossRef] [PubMed]

19. Pagani, L.; Eckert, A. Amyloid-Beta Interaction with Mitochondria. Int. J. Alzheimer's Dis. 2011, 2011, 1-12. [CrossRef] [PubMed]

20. Lustbader, J.W.; Cirilli, M.; Lin, C.; Xu, H.W.; Takuma, K.; Wang, N.; Caspersen, C.; Chen, X.; Pollak, S.; Chaney, M.; et al. ABAD Directly Links Abeta to Mitochondrial Toxicity in Alzheimer's Disease. Science 2004, 304, 448-452. [CrossRef] [PubMed]

21. Manczak, M.; Calkins, M.J.; Reddy, P.H. Impaired Mitochondrial Dynamics and Abnormal Interaction of Amyloid Beta with Mitochondrial Protein Drp1 in Neurons from Patients with Alzheimer's Disease: Implications for Neuronal Damage. Hum. Mol. Genet. 2011, 20, 2495-2509. [CrossRef]

22. Yao, J.; Irwin, R.W.; Zhao, L.; Nilsen, J.; Hamilton, R.T.; Brinton, R.D. Mitochondrial Bioenergetic Deficit Precedes Alzheimer's Pathology in Female Mouse Model of Alzheimer's Disease. Proc. Natl. Acad. Sci. USA 2009, 106, 14670-14675. [CrossRef] [PubMed]

23. Rhein, V.; Song, X.; Wiesner, A.; Ittner, L.M.; Baysang, G.; Meier, F.; Ozmen, L.; Bluethmann, H.; Drose, S.; Brandt, U.; et al. Amyloid- and Tau Synergistically Impair the Oxidative Phosphorylation System in Triple Transgenic Alzheimer's Disease Mice. Proc. Natl. Acad. Sci. USA 2009, 106, 20057-20062. [CrossRef]

24. Morais, V.A.; De Strooper, B. Mitochondria Dysfunction and Neurodegenerative Disorders: Cause or Consequence. JAD 2010, 20, S255-S263. [CrossRef]

25. Selfridge, J.E.; Lezi, E.; Lu, J.; Swerdlow, R.H. Role of Mitochondrial Homeostasis and Dynamics in Alzheimer's Disease. Neurobiol. Dis. 2013, 51, 3-12. [CrossRef]

26. Pinho, C.M.; Teixeira, P.F.; Glaser, E. Mitochondrial Import and Degradation of Amyloid- $\beta$ Peptide. Biochim. Biophys. Acta (BBA)-Bioenerg. 2014, 1837, 1069-1074. [CrossRef] [PubMed]

27. Swerdlow, R.H.; Khan, S.M. A “Mitochondrial Cascade Hypothesis” for Sporadic Alzheimer's Disease. Med. Hypotheses 2004, 63, 8-20. [CrossRef]

28. Rugarli, E.I.; Langer, T. Mitochondrial Quality Control: A Matter of Life and Death for Neurons: Mitochondrial Quality Control and Neurodegeneration. EMBO J. 2012, 31, 1336-1349. [CrossRef] [PubMed]

29. Schmidt, O.; Pfanner, N.; Meisinger, C. Mitochondrial Protein Import: From Proteomics to Functional Mechanisms. Nat. Rev. Mol. Cell Biol. 2010, 11, 655-667. [CrossRef] [PubMed]

30. Bolender, N.; Sickmann, A.; Wagner, R.; Meisinger, C.; Pfanner, N. Multiple Pathways for Sorting Mitochondrial Precursor Proteins. EMBO Rep. 2008, 9, 42-49. [CrossRef] [PubMed]

31. Hawlitschek, G.; Schneider, H.; Schmidt, B.; Tropschug, M.; Hartl, F.-U.; Neupert, W. Mitochondrial Protein Import: Identification of Processing Peptidase and of PEP, a Processing Enhancing Protein. Cell 1988, 53, 795-806. [CrossRef]

32. Yang, M.J.; Geli, V.; Oppliger, W.; Suda, K.; James, P.; Schatz, G. The MAS-Encoded Processing Protease of Yeast Mitochondria. Interaction of the Purified Enzyme with Signal Peptides and a Purified Precursor Protein. J. Biol. Chem. 1991, 266, 6416-6423. [CrossRef]

33. Vögtle, F.-N.; Wortelkamp, S.; Zahedi, R.P.; Becker, D.; Leidhold, C.; Gevaert, K.; Kellermann, J.; Voos, W.; Sickmann, A.; Pfanner, N.; et al. Global Analysis of the Mitochondrial N-Proteome Identifies a Processing Peptidase Critical for Protein Stability. Cell 2009, 139, 428-439. [CrossRef] [PubMed]

34. Vögtle, F.-N.; Prinz, C.; Kellermann, J.; Lottspeich, F.; Pfanner, N.; Meisinger, C. Mitochondrial Protein Turnover: Role of the Precursor Intermediate Peptidase Oct1 in Protein Stabilization. MBoC 2011, 22, 2135-2143. [CrossRef] [PubMed]

35. Mossmann, D.; Meisinger, C.; Vögtle, F.-N. Processing of Mitochondrial Presequences. Biochim. Biophys. Acta (BBA)-Gene Regul. Mech. 2012, 1819, 1098-1106. [CrossRef]

36. Teixeira, P.F.; Glaser, E. Processing Peptidases in Mitochondria and Chloroplasts. Biochim. Biophys. Acta (BBA)-Mol. Cell Res. 2013, 1833, 360-370. [CrossRef]

37. Kücükköse, C.; Taskin, A.A.; Marada, A.; Brummer, T.; Dennerlein, S.; Vögtle, F. Functional Coupling of Presequence Processing and Degradation in Human Mitochondria. FEBS J. 2021, 288, 600-613. [CrossRef] [PubMed]

38. Ståhl, A.; Nilsson, S.; Lundberg, P.; Bhushan, S.; Biverståhl, H.; Moberg, P.; Morisset, M.; Vener, A.; Mäler, L.; Langel, U.; et al. Two Novel Targeting Peptide Degrading Proteases, PrePs, in Mitochondria and Chloroplasts, so Similar and Still Different. J. Mol. Biol. 2005, 349, 847-860. [CrossRef] 
39. Kambacheld, M.; Augustin, S.; Tatsuta, T.; Müller, S.; Langer, T. Role of the Novel Metallopeptidase MoP112 and Saccharolysin for the Complete Degradation of Proteins Residing in Different Subcompartments of Mitochondria. J. Biol. Chem. 2005, 280, 20132-20139. [CrossRef]

40. Taylor, A.B.; Smith, B.S.; Kitada, S.; Kojima, K.; Miyaura, H.; Otwinowski, Z.; Ito, A.; Deisenhofer, J. Crystal Structures of Mitochondrial Processing Peptidase Reveal the Mode for Specific Cleavage of Import Signal Sequences. Structure 2001, 9, 615-625. [CrossRef]

41. Mzhavia, N.; Berman, Y.L.; Qian, Y.; Yan, L.; Devi, L.A. Cloning, Expression, and Characterization of Human Metalloprotease 1: A Novel Member of the Pitrilysin Family of Metalloendoproteases. DNA Cell Biol. 1999, 18, 369-380. [CrossRef] [PubMed]

42. King, J.V.; Liang, W.G.; Scherpelz, K.P.; Schilling, A.B.; Meredith, S.C.; Tang, W.-J. Molecular Basis of Substrate Recognition and Degradation by Human Presequence Protease. Structure 2014, 22, 996-1007. [CrossRef] [PubMed]

43. Falkevall, A.; Alikhani, N.; Bhushan, S.; Pavlov, P.F.; Busch, K.; Johnson, K.A.; Eneqvist, T.; Tjernberg, L.; Ankarcrona, M.; Glaser, E. Degradation of the Amyloid $\beta$-Protein by the Novel Mitochondrial Peptidasome, PreP. J. Biol. Chem. 2006, 281, 29096-29104. [CrossRef] [PubMed]

44. Johnson, K.A.; Bhushan, S.; Ståhl, A.; Hallberg, B.M.; Frohn, A.; Glaser, E.; Eneqvist, T. The Closed Structure of Presequence Protease PreP Forms a Unique 10000 Å3 Chamber for Proteolysis. EMBO J. 2006, 25, 1977-1986. [CrossRef] [PubMed]

45. Taskin, A.A.; Kücükköse, C.; Burger, N.; Mossmann, D.; Meisinger, C.; Vögtle, F.-N. The Novel Mitochondrial Matrix Protease Ste23 Is Required for Efficient Presequence Degradation and Processing. MBoC 2017, 28, 997-1002. [CrossRef]

46. Im, H.; Manolopoulou, M.; Malito, E.; Shen, Y.; Zhao, J.; Neant-Fery, M.; Sun, C.-Y.; Meredith, S.C.; Sisodia, S.S.; Leissring, M.A.; et al. Structure of Substrate-Free Human Insulin-Degrading Enzyme (IDE) and Biophysical Analysis of ATP-Induced Conformational Switch of IDE. J. Biol. Chem. 2007, 282, 25453-25463. [CrossRef]

47. Björk, B.F.; Katzov, H.; Kehoe, P.; Fratiglioni, L.; Winblad, B.; Prince, J.A.; Graff, C. Positive Association between Risk for Late-Onset Alzheimer Disease and Genetic Variation in IDE. Neurobiol. Aging 2007, 28, 1374-1380. [CrossRef]

48. González-Casimiro, C.M.; Merino, B.; Casanueva-Álvarez, E.; Postigo-Casado, T.; Cámara-Torres, P.; Fernández-Díaz, C.M.; Leissring, M.A.; Cózar-Castellano, I.; Perdomo, G. Modulation of Insulin Sensitivity by Insulin-Degrading Enzyme. Biomedicines 2021, 9, 86. [CrossRef]

49. Alikhani, N.; Guo, L.; Yan, S.; Du, H.; Pinho, C.M.; Chen, J.X.; Glaser, E.; Yan, S.S. Decreased Proteolytic Activity of the Mitochondrial Amyloid- $\beta$ Degrading Enzyme, PreP Peptidasome, in Alzheimer's Disease Brain Mitochondria. JAD 2011, 27, 75-87. [CrossRef]

50. Sekar, S.; McDonald, J.; Cuyugan, L.; Aldrich, J.; Kurdoglu, A.; Adkins, J.; Serrano, G.; Beach, T.G.; Craig, D.W.; Valla, J.; et al. Alzheimer's Disease Is Associated with Altered Expression of Genes Involved in Immune Response and Mitochondrial Processes in Astrocytes. Neurobiol. Aging 2015, 36, 583-591. [CrossRef] [PubMed]

51. Begcevic, I.; Kosanam, H.; Martínez-Morillo, E.; Dimitromanolakis, A.; Diamandis, P.; Kuzmanov, U.; Hazrati, L.-N.; Diamandis, E.P. Semiquantitative Proteomic Analysis of Human Hippocampal Tissues from Alzheimer's Disease and Age-Matched Control Brains. Clin. Proteom. 2013, 10, 5. [CrossRef]

52. Niedzielska, E.; Smaga, I.; Gawlik, M.; Moniczewski, A.; Stankowicz, P.; Pera, J.; Filip, M. Oxidative Stress in Neurodegenerative Diseases. Mol. Neurobiol. 2016, 53, 4094-4125. [CrossRef]

53. Chen, J.; Teixeira, P.F.; Glaser, E.; Levine, R.L. Mechanism of Oxidative Inactivation of Human Presequence Protease by Hydrogen Peroxide. Free. Radic. Biol. Med. 2014, 77, 57-63. [CrossRef]

54. Kierdorf, K.; Fritz, G. RAGE Regulation and Signaling in Inflammation and Beyond. J. Leukoc. Biol. 2013, 94, 55-68. [CrossRef]

55. Sparvero, L.J.; Asafu-Adjei, D.; Kang, R.; Tang, D.; Amin, N.; Im, J.; Rutledge, R.; Lin, B.; Amoscato, A.A.; Zeh, H.J.; et al. RAGE (Receptor for Advanced Glycation Endproducts), RAGE Ligands, and Their Role in Cancer and Inflammation. J. Transl. Med. 2009, 7, 17. [CrossRef]

56. Fang, D.; Wang, Y.; Zhang, Z.; Du, H.; Yan, S.; Sun, Q.; Zhong, C.; Wu, L.; Vangavaragu, J.R.; Yan, S.; et al. Increased Neuronal PreP Activity Reduces A $\beta$ Accumulation, Attenuates Neuroinflammation and Improves Mitochondrial and Synaptic Function in Alzheimer Disease's Mouse Model. Hum. Mol. Genet. 2015, 24, 5198-5210. [CrossRef] [PubMed]

57. Xu, Y.-J.; Mei, Y.; Qu, Z.-L.; Zhang, S.-J.; Zhao, W.; Fang, J.-S.; Wu, J.; Yang, C.; Liu, S.-J.; Fang, Y.-Q.; et al. Ligustilide Ameliorates Memory Deficiency in APP/PS1 Transgenic Mice via Restoring Mitochondrial Dysfunction. BioMed Res. Int. 2018, $2018,1-15$. [CrossRef] [PubMed]

58. Brunetti, D.; Bottani, E.; Segala, A.; Marchet, S.; Rossi, F.; Orlando, F.; Malavolta, M.; Carruba, M.O.; Lamperti, C.; Provinciali, M.; et al. Targeting Multiple Mitochondrial Processes by a Metabolic Modulator Prevents Sarcopenia and Cognitive Decline in SAMP8 Mice. Front. Pharmacol. 2020, 11, 1171. [CrossRef]

59. Morley, J.E.; Armbrecht, H.J.; Farr, S.A.; Kumar, V.B. The Senescence Accelerated Mouse (SAMP8) as a Model for Oxidative Stress and Alzheimer's Disease. Biochim. Biophys. Acta (BBA)-Mol. Basis Dis. 2012, 1822, 650-656. [CrossRef] [PubMed]

60. Du, F.; Yu, Q.; Yan, S.; Zhang, Z.; Vangavaragu, J.R.; Chen, D.; Yan, S.F.; Yan, S.S. Gain of PITRM1 Peptidase in Cortical Neurons Affords Protection of Mitochondrial and Synaptic Function in an Advanced Age Mouse Model of Alzheimer's Disease. Aging Cell 2021, 20. [CrossRef]

61. Vangavaragu, J.R.; Valasani, K.R.; Gan, X.; Yan, S.S. Identification of Human Presequence Protease (HPreP) Agonists for the Treatment of Alzheimer's Disease. Eur. J. Med. Chem. 2014, 76, 506-516. [CrossRef] 
62. Li, N.-S.; Liang, W.; Piccirilli, J.A.; Tang, W.-J. Reinvestigating the Synthesis and Efficacy of Small Benzimidazole Derivatives as Presequence Protease Enhancers. Eur. J. Med. Chem. 2019, 184, 111746. [CrossRef] [PubMed]

63. Grupe, A.; Li, Y.; Rowland, C.; Nowotny, P.; Hinrichs, A.L.; Smemo, S.; Kauwe, J.S.K.; Maxwell, T.J.; Cherny, S.; Doil, L.; et al. A Scan of Chromosome 10 Identifies a Novel Locus Showing Strong Association with Late-Onset Alzheimer Disease. Am. J. Hum. Genet. 2006, 78, 78-88. [CrossRef] [PubMed]

64. Pinho, C.M.; Björk, B.F.; Alikhani, N.; Bäckman, H.G.; Eneqvist, T.; Fratiglioni, L.; Glaser, E.; Graff, C. Genetic and Biochemical Studies of SNPs of the Mitochondrial A $\beta$-Degrading Protease, HPreP. Neurosci. Lett. 2010, 469, 204-208. [CrossRef]

65. Brunetti, D.; Torsvik, J.; Dallabona, C.; Teixeira, P.; Sztromwasser, P.; Fernandez-Vizarra, E.; Cerutti, R.; Reyes, A.; Preziuso, C.; D'Amati, G.; et al. Defective PITRM 1 Mitochondrial Peptidase Is Associated with A $\beta$ Amyloidotic Neurodegeneration. EMBO Mol. Med. 2016, 8, 176-190. [CrossRef] [PubMed]

66. Motter, R.; Vigo-Pelfrey, C.; Kholodenko, D.; Barbour, R.; Johnson-Wood, K.; Galasko, D.; Chang, L.; Miller, B.; Clark, C.; Green, R.; et al. Reduction of ?-Amyloid Peptide42 in the Cerebrospinal Fluid of Patients with Alzheimer's Disease. Ann. Neurol. 1995, 38, 643-648. [CrossRef]

67. Andreasen, N.; Hesse, C.; Davidsson, P.; Minthon, L.; Wallin, A.; Winblad, B.; Vanderstichele, H.; Vanmechelen, E.; Blennow, K. Cerebrospinal Fluid $\beta$-Amyloid(1-42) in Alzheimer Disease: Differences Between Early- and Late-Onset Alzheimer Disease and Stability During the Course of Disease. Arch. Neurol. 1999, 56, 673. [CrossRef]

68. Smith-Carpenter, J.E.; Alper, B.J. Functional Requirement for Human Pitrilysin Metallopeptidase 1 Arginine 183, Mutated in Amyloidogenic Neuropathy: Pitrm1 Residue R183 Identity Is Critical to Peptide Hydrolysis. Protein Sci. 2018, 27, 861-873. [CrossRef] [PubMed]

69. Langer, Y.; Aran, A.; Gulsuner, S.; Abu Libdeh, B.; Renbaum, P.; Brunetti, D.; Teixeira, P.-F.; Walsh, T.; Zeligson, S.; Ruotolo, R.; et al. Mitochondrial PITRM1 Peptidase Loss-of-Function in Childhood Cerebellar Atrophy. J. Med. Genet. 2018, 55, 599-606. [CrossRef]

70. Tolomeo, D.; Rubegni, A.; Nesti, C.; Barghigiani, M.; Battini, R.; D’Amore, F.; Doccini, S.; Donati, M.A.; Galatolo, D.; Giglio, S.; et al. Learning from Massive Testing of Mitochondrial Disorders: UPD Explaining Unorthodox Transmission. J. Med. Genet. 2021. [CrossRef]

71. Hytönen, M.K.; Sarviaho, R.; Jackson, C.B.; Syrjä, P.; Jokinen, T.; Matiasek, K.; Rosati, M.; Dallabona, C.; Baruffini, E.; Quintero, I.; et al. In-Frame Deletion in Canine PITRM1 Is Associated with a Severe Early-Onset Epilepsy, Mitochondrial Dysfunction and Neurodegeneration. Hum. Genet. 2021. [CrossRef]

72. Reddy, B.; Kelawala, D.N.; Shah, T.; Patel, A.B.; Patil, D.B.; Parikh, P.V.; Patel, N.; Parmar, N.; Mohapatra, A.B.; Singh, K.M.; et al. Identification of Putative SNPs in Progressive Retinal Atrophy Affected Canis Lupus Familiaris Using Exome Sequencing. Mamm. Genome 2015, 26, 638-649. [CrossRef]

73. Weidling, I.; Swerdlow, R.H. Mitochondrial Dysfunction and Stress Responses in Alzheimer's Disease. Biology $2019,8,39$. [CrossRef]

74. Sharma, V.K.; Singh, T.G.; Mehta, V. Stressed Mitochondria: A Target to Intrude Alzheimer's Disease. Mitochondrion 2021, 59, 48-57. [CrossRef]

75. Mossmann, D.; Vögtle, F.-N.; Taskin, A.A.; Teixeira, P.F.; Ring, J.; Burkhart, J.M.; Burger, N.; Pinho, C.M.; Tadic, J.; Loreth, D.; et al. Amyloid- $\beta$ Peptide Induces Mitochondrial Dysfunction by Inhibition of Preprotein Maturation. Cell Metab. 2014, 20, 662-669. [CrossRef] [PubMed]

76. Pérez, M.J.; Ivanyuk, D.; Panagiotakopoulou, V.; Di Napoli, G.; Kalb, S.; Brunetti, D.; Al-Shaana, R.; Kaeser, S.A.; Fraschka, S.A.-K.; Jucker, M.; et al. Loss of Function of the Mitochondrial Peptidase PITRM1 Induces Proteotoxic Stress and Alzheimer's Disease-like Pathology in Human Cerebral Organoids. Mol. Psychiatry 2020. [CrossRef] [PubMed]

77. S Beck, J.; J Mufson, E.; E Counts, S. Evidence for Mitochondrial UPR Gene Activation in Familial and Sporadic Alzheimer's Disease. CAR 2016, 13, 610-614. [CrossRef]

78. Melber, A.; Haynes, C.M. UPRmt Regulation and Output: A Stress Response Mediated by Mitochondrial-Nuclear Communication. Cell Res. 2018, 28, 281-295. [CrossRef] [PubMed]

79. Navarro, J.F.; Croteau, D.L.; Jurek, A.; Andrusivova, Z.; Yang, B.; Wang, Y.; Ogedegbe, B.; Riaz, T.; Støen, M.; Desler, C.; et al. Spatial Transcriptomics Reveals Genes Associated with Dysregulated Mitochondrial Functions and Stress Signaling in Alzheimer Disease. Iscience 2020, 23, 101556. [CrossRef]

80. Pakos-Zebrucka, K.; Koryga, I.; Mnich, K.; Ljujic, M.; Samali, A.; Gorman, A.M. The Integrated Stress Response. EMBO Rep. 2016, 17, 1374-1395. [CrossRef]

81. Chen, J.X.; Yan, S.S. Role of Mitochondrial Amyloid- $\beta$ in Alzheimer's Disease. JAD 2010, 20, S569-S578. [CrossRef]

82. Dragicevic, N.; Mamcarz, M.; Zhu, Y.; Buzzeo, R.; Tan, J.; Arendash, G.W.; Bradshaw, P.C. Mitochondrial Amyloid- $\beta$ Levels Are Associated with the Extent of Mitochondrial Dysfunction in Different Brain Regions and the Degree of Cognitive Impairment in Alzheimer's Transgenic Mice. JAD 2010, 20, S535-S550. [CrossRef]

83. Sorrentino, V.; Romani, M.; Mouchiroud, L.; Beck, J.S.; Zhang, H.; D’Amico, D.; Moullan, N.; Potenza, F.; Schmid, A.W.; Rietsch, S.; et al. Enhancing Mitochondrial Proteostasis Reduces Amyloid- $\beta$ Proteotoxicity. Nature 2017, 552, 187-193. [CrossRef]

84. Sidrauski, C.; McGeachy, A.M.; Ingolia, N.T.; Walter, P. The Small Molecule ISRIB Reverses the Effects of EIF2 $\alpha$ Phosphorylation on Translation and Stress Granule Assembly. eLife 2015, 4, e05033. [CrossRef] 
85. Poveda-Huertes, D.; Matic, S.; Marada, A.; Habernig, L.; Licheva, M.; Myketin, L.; Gilsbach, R.; Tosal-Castano, S.; Papinski, D.; Mulica, P.; et al. An Early MtUPR: Redistribution of the Nuclear Transcription Factor Rox1 to Mitochondria Protects against Intramitochondrial Proteotoxic Aggregates. Mol. Cell 2020, 77, 180-188.e9. [CrossRef]

86. Aman, Y.; Frank, J.; Lautrup, S.H.; Matysek, A.; Niu, Z.; Yang, G.; Shi, L.; Bergersen, L.H.; Storm-Mathisen, J.; Rasmussen, L.J.; et al. The NAD+-Mitophagy Axis in Healthy Longevity and in Artificial Intelligence-Based Clinical Applications. Mech. Ageing Dev. 2020, 185, 111194. [CrossRef] [PubMed]

87. Tanaka, M.; Toldi, J.; Vécsei, L. Exploring the Etiological Links behind Neurodegenerative Diseases: Inflammatory Cytokines and Bioactive Kynurenines. IJMS 2020, 21, 2431. [CrossRef] [PubMed]

88. Brosseron, F.; Krauthausen, M.; Kummer, M.; Heneka, M.T. Body Fluid Cytokine Levels in Mild Cognitive Impairment and Alzheimer's Disease: A Comparative Overview. Mol. Neurobiol. 2014, 50, 534-544. [CrossRef] [PubMed]

89. Gomez-Fabra Gala, M.; Vögtle, F. Mitochondrial Proteases in Human Diseases. FEBS Lett. 2021, 595, 1205-1222. [CrossRef]

90. Du, J.; Zhang, L.; Liu, S.; Zhang, C.; Huang, X.; Li, J.; Zhao, N.; Wang, Z. PPAR $\gamma$ Transcriptionally Regulates the Expression of Insulin-Degrading Enzyme in Primary Neurons. Biochem. Biophys. Res. Commun. 2009, 383, 485-490. [CrossRef]

91. Song, E.S.; Jang, H.; Guo, H.-F.; Juliano, M.A.; Juliano, L.; Morris, A.J.; Galperin, E.; Rodgers, D.W.; Hersh, L.B. Inositol Phosphates and Phosphoinositides Activate Insulin-Degrading Enzyme, While Phosphoinositides Also Mediate Binding to Endosomes. Proc. Natl. Acad. Sci. USA 2017, 114, E2826-E2835. [CrossRef] [PubMed]

92. Bottani, E.; Lamperti, C.; Prigione, A.; Tiranti, V.; Persico, N.; Brunetti, D. Therapeutic Approaches to Treat Mitochondrial Diseases: "One-Size-Fits-All" and "Precision Medicine" Strategies. Pharmaceutics 2020, 12, 1083. [CrossRef] [PubMed] 